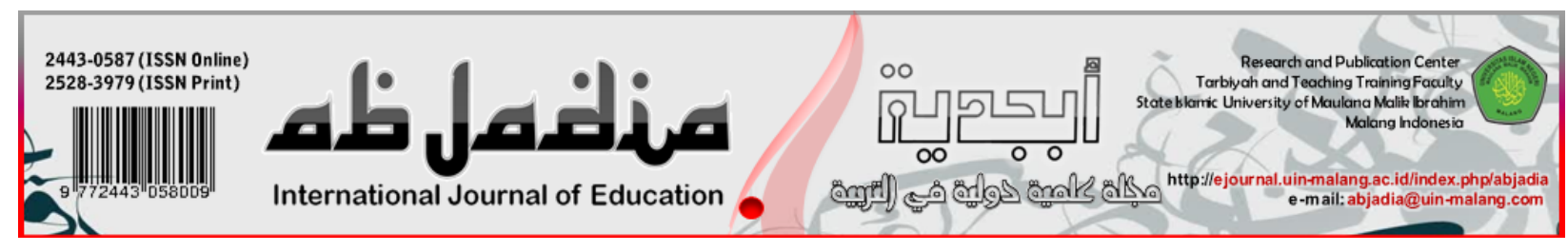

\title{
LISTENING STRATEGY: A LINK BETWEEN GENDER AND STUDENT'S ACHIEVEMENT
}

\author{
Ika Hidayanti ${ }^{1}$, Atik Umamah ${ }^{2}$ \\ 1,2 Universitas Islam Malang, Indonesia
}

Article History:

Received : 2019-01-12

Revised : 2019-01-31

Accepted : 2019-01-30

Published : 2019-06-30

\section{Keywords:}

Learning Strategy, Listening Skill,

Gender, Proficiency

\begin{abstract}
The recent study is investigating 1) the significant difference on the use of learning strategy by male and female students in listening, and 2) the correlation between the learning strategy use and two aspects of gender and listening proficiency. The questionnaire was directed to 140 university students to answer a-85 item of learning strategy. The t-test and correlation analysis were used to analyse the research problems. The first finding reveals that female students did not deploy the strategies significantly different from the male counterparts. The later result reports that there was no correlation between listening strategy and two factors of gender and the students' listening achievement.
\end{abstract}

Correspondence Address:

\section{(C) Introduction}

Research on skill-based learning strategies has gained widespread attention and has been carried out in various contexts all over the world. The focus of this research was primarily on certain English skill such as listening, speaking, reading, or writing. In terms of listening skill, a lot of research was conducted to deal with different issues. The issues are related to listening strategy preference by different groups of learners (Abid, Daghir, \& Ridha, 2010; Ghoneim, 2013; Zuhairi \& Hidayanti, 2016; Hidayanti \& Umamah, 2018), correlation between strategy preference and proficiency (Bidabadi \& Yamat, 2011; Yulisa, 2018), the deployment of certain strategy category (Vandergrift, Goh, \& Mareschal, 2006; Bozorgian \& Pillay, 2013), and strategies-based instruction (Jin, 2002; Abid, Daghir, \& Ridha, 2010; Ivarsson \& Palm, 2013; Bao, 2017).

In terms of listening strategy preference by different groups of learners, Abid, Daghir, and Ridha (2010) found that EFL Iraqi learners applied the strategies at moderate level with the most intensively used strategies are metacognitive strategies and the least frequently used ones are compensation strategies. In addition, high achievers were reported to use the strategies more frequently than the lower achievers. Ghoneim (2013) examined the problems that university students (advanced and intermediate) in Egypt face in listening class, the mental processes they activate in listening comprehension, and 
the strategies they apply in different phases of comprehension. The findings show that both groups encountered the same problems, activated three groups of processes (comprehension-gathering, linguistic, and connecting processes), and the advanced group students deployed top down strategies more than the intermediate counterpart did.

In addition, Zuhairi and Hidayanti (2016) conducted a strategy research in the context of Indonesian junior high school. They report that Indonesian junior high school students are medium strategy users with compensation strategies taken as the most frequent and social strategies at the least frequent. With regard to the inter-correlation among the strategy categories, it is reported that some strategies were found to have positive and significant interrelation, while some others were not significantly correlated. Meanwhile, both groups of high and low achievers were not significantly different in their use of listening strategies. In 2018, Hidayanti and Umamah studied the profile of learning strategies used by Indonesian university students. They revealed that the use of strategies was at moderate level with selective attention strategies considered the most frequently used category and social developing strategy as the least. This research also reports that successful learners deployed more strategies than the less successful ones. Based on the review above, it can be concluded that the findings of those studies are not far different in which the intensity of use is at moderate and successful learners employ the strategies more intensively than the counterpart does.

Regarding with the correlation between strategy preference and listening proficiency, Bidabadi and Yamat (2011) and Yulisa (2018) report similar finding. They found that the use of learning strategy and listening proficiency correlated significantly and positively. In other words, strategy can be predictor to the students' listening achievement. Furthermore, some studies also shifted their focus on the deployment of certain strategy category. Vandergrift, Goh, and Mareschal (2006) developed Metacognitive Awareness Listening Questionnaire (MALQ) comprising of five categories: problem solving, planning and evaluation, mental translation, person knowledge, and directed attention. Metacognitive awareness is regarded essential to encourage the students to learn how to be better listeners.

The last issue is related to strategies-based instruction. Jin (2002) found the positive influence of teaching strategies on the students' achievement. Along the same line, Bozorgian and Pillay (2013) examined whether teaching listening strategies delivered in L1 (Persian) was effective and whether this kind of strategy based instruction influences the students' listening comprehension in L2. Statistically, this research found that there is a significant improvement in the students' discrete listening scores compared with the control group. Further, Bao (2017) reported that strategies taught by teachers were at medium level with meta-cognitive strategy as the highest. This research also indicated that strategies teachers instruct and strategies student use have positive correlation although there is a certain gap on the application of social/affective strategies. Teachers consider cognitive strategy and social/affective strategies to have equal importance, but 
in fact students seldom apply social/affective strategies. To sum, these three research reports convincingly prove that strategies based instruction offers a positive effect on students' improvement in listening proficiency.

Based on the review presented above, it can be noted that not all factors influencing strategy choice have been investigated comprehensively especially in terms of gender. Whereas, learning strategies can be predicted from a number of factors such as gender, proficiency level, motivation, personality, and language aptitude (Oxford \& Ehrman, 1995; Huda, 1998). Therefore, this current research is carried out to pose two problems: 1) does the use of the strategy in learning listening have significant difference with regard to gender? and 2) does the learning strategy deployment correlate with gender and the students' listening proficiency?

\section{[Q] Method}

Utilizing SPSS 20 (Pallant, 2011) for the independent t-Test and correlation analysis, this research was aimed at identifying the difference on the strategy employment by female and male learners, and the correlation between the choice of the learning strategy and the two factors of gender and student's listening achievement. 140 university students enrolling at English Department of Universitas Islam Malang. They were asked to answer 85 items of questionnaire which was adopted from A posteriori taxonomy of strategies of learning English listening (Zuhairi \& Hidayanti, 2014). Having been analysed, the correlation was interpreted large if the $\mathrm{r}=.50$ to 1.0 or $\mathrm{r}=-.50$ to -.1 .0 , medium if the $r=.30$ to .49 or $r=-.30$ to -.49 , and small if the $r=.10$ to .29 or $r=-.10$ to -.29 (Cohen, 1988 cited in Pallant, 2011).

\section{Result}

Question 1: Are there any significant difference in the use of learning strategies in listening by male and female students?

The statistical result is presented in Table 1. It is obvious that among fourteen strategy categories, female students selected ten strategies to comprehend the listening, moreover, it accounts higher mean on self-negotiating, context-based, self-monitoring, selective attention, resources-processing, form-focused, compensation, input-output, scanning, and interaction-based strategies. In opposite, male used the latter four strategies of social-developing, metacognitive, cognitive, and self-developing strategies. However, in terms of overall use of the learning strategies, there is no significant difference between the two groups of gender.

Table 1 The Difference in the Use of Strategies of Learning Listening by Female Students $(N=100)$ and Male Students $(N=40)$

\begin{tabular}{lccc}
\hline Strategy Categories & Gender & Mean (S.D) & Mean Difference \\
\hline Self-developing Strategies & Female & $3.14(.48)$ & .0 \\
& Male & $3.14(.43)$ & \\
Resources-processing Strategies & Female & $3.48(.57)$ & .20 \\
\hline
\end{tabular}




\begin{tabular}{lccc}
\hline & Male & $3.28(.42)$ & \\
Interaction-based Strategies & Female & $3.36(.52)$ & .11 \\
& Male & $3.25(.39)$ & \\
Scanning Strategies & Female & $3.13(.57)$ & .04 \\
Form-focused Strategies & Male & $3.09(.54)$ & \\
& Female & $3.51(.55)$ & .13 \\
Metacognitive Strategies & Male & $3.38(.60)$ & \\
& Female & $3.12(.74)$ & -.11 \\
Selective Attention Strategies & Male & $3.23(.57)$ & \\
& Female & $3.73(.65)$ & .13 \\
Self-monitoring Strategies & Male & $3.60(.58)$ & \\
& Female & $3.51(.63)$ & .25 \\
Compensation Strategies & Male & $3.26(.63)$ & \\
& Female & $3.53(.56)$ & .12 \\
Cognitive Strategies & Male & $3.41(.59)$ & \\
& Female & $3.17(.78)$ & -.06 \\
Input-output Strategies & Male & $3.23(.61)$ & \\
& Female & $3.26(.63)$ & .06 \\
Self-negotiating Strategies & Male & $3.20(.63)$ & \\
& Female & $3.69(.77)$ & .31 \\
Contex-based Strategy & Male & $3.38(.67)$ & \\
& Female & $3.47(.88)$ & .24 \\
Social-developing Strategy & Male & $3.23(.91)$ & \\
& Female & $2.61(1.26)$ & -.47 \\
& Male & $3.08(1.26)$ & \\
& &
\end{tabular}

Question 2: Does the use of learning strategies correlate with gender and listening achievement?

The finding reveals that there is no correlation between the strategy attainment and gender $(\mathrm{r}=.068)$. Besides, the finding shows that the choice of the learning strategies did not correlate with the listening achievement $(r=-.035)$.

\section{نَiin Discussion}

Having been analysed, the first finding reveals that the overall use of the learning strategies in listening did not show significant different from both gender. Meanwhile, in terms of correlation, it was reported that there was no correlation between the learning strategy choice and the two factors of different gender and their listening proficiency.

Altough it confirms that there is no significant difference on the learning strategy choice, female learners deployed more strategies than males. They applied selfnegotiating, context-based, self-monitoring, selective attention, resources-processing, form-focused, compensation, input-output, scanning, and interaction-based strategies. To improve the listening skill, female learners tend to engage themselves on listening to some extra resources such as song and movies to enrich their English vocabularies. In whilst listening phase, they like to take some notes too. Besides, to gain the idea of the speaker, they focus on some keywords or visual clues and pay attention to the beginning word of the sentence (e.g. Do you....?, Are you.....?, What is.....?) while listening to English. Sometimes, they focus on the native speaker's rhythm and intonation to get understanding on the listening passages.

In opposite, male used the latter four strategies of social-developing, metacognitive, cognitive, and self-developing strategies. They chose to practice speaking with natives to 
get familiar with listening to English. To comprehend the aural texts, male learners focus on identifying the sound of the word to the sound of familiar word and look for similarities and differences between English and their native language. After that they guess the meaning or translate it into their native language. This confirms Vandergrift, Goh, and Mareschal (2006) who stated that Metacognitive awareness is necessary to build a better listener.

The first finding was in line with Abid, Daghir and Ridha (2010) who also found the there is no significant different on the overall use of the learning strategy choice in listening. In terms of correlation, this result confirms the study from Zuhairi and Hidayanti (2016).

\section{Conclusion}

To sum up, the recent study reveals that overall the female and male learners deployed the learning strategy not significantly different. Beside, between the strategy choice and the two aspects of gender and listening proficiency confirmed not significantly correlated. However, the result on the learning startegy attainment by the learners imply that, pedagogically, it is necessary to apply the strategy-based instruction for EFL students, especially in learning listening.

\section{Bibliography}

Adib, R. A., Daghir, S. C., \& Ridha, N. S. (2010). Investigating the relationship between learner's gender, proficiency and language learning strategies: The case of EFL Iraqi learners. Journal of the College of Arts. University of Basrah(53), 32-56. Retrieved from https://www.iasj.net/iasj?func=article\&aId $=56681$

Bao, X. (2017). A study on listening strategies instructed by teachers and strategies used by students. International Journal of English Linguistics, 7(2), 186-195.

doi:10.5539/ijel.v7n2p186

Bidabadi, F. S., \& Yamat, H. (2011). The relationship between listening strategies used by Iranian EFL freshman university students and their listening proficiency levels. English Language Teaching, 4(1), 26-32. Retrieved from www.ccsenet.org/journal/index.php/elt/article/view/9703

Bozorgian, H., \& Pillay, H. (2013). Enhancing foreign language learning through listening strategies delivered in L1: An experimental study. International Journal of Instruction, 6(1), 105-122. Retrieved from https:/ / eric.ed.gov/?id=EJ1085363

Ghoneim, N. M. (2013). The listening comprehension strategies used by college students to cope with the aural problems in EFL classes: An analytical study. English Language Teaching, 6(2), 100-112. doi:10.5539/elt.v6n2p100 
Hidayanti, I., \& Umamah, A. (2018). Listening strategy preference by non-native English university students. The paper is presented in international conference, 4th ELTEAM \& 1st COETIN at Muhammadiyah University Malang, 27-29 November 2018.

Huda, N. (1998). Relationship between speaking proficiency, reflectivity-impulsivity, and L2 learning strategies. In W. A. Renandya, \& G. M. Jacobs, Learners and language learning (pp. 40-55). Singapore: SEAMEO Regional Language Center.

Jin, K.-A. (2002). The effect of teaching listening strategies in the EFL classroom. Language Research, 38(3), 987-999. Retrieved from sspace.snu.ac.kr/bitstream/10371/86216/1/11.\%202225605.pdf

Oxford, R. L., \& Ehrman, M. E. (1995). Adult's language learning strategies in an intensive foreign language program in the United States. System, 23(3), 359-386. Retrieved from https://www.sciencedirect.com/science/article/pii/0346251X9500023D

Pallant, J.F. (2011). SPSS Survival Manual: A Step-by-step Guide to Data Analysis Using SPSS. Crows Nest, NSW: Allen \& Unwin.

Vandergrift, L., Goh, C. C., Mareschal, C. J., \& Tafaghodtari, M. H. (2006). The metacognitive awareness listening questionnaire: Development and validation. Language Learning, 56(3), 431-462. Retrieved from https:/ / onlinelibrary.wiley.com/doi/abs/10.1111/j.14679922.2006.00373.x

Yulisa, D. (2018). Learning to listen: Listening strategies and listening comprehension of Islamic senior high school students. Edukasi Pendidikan Dan Pengajar, 5(1), 22-30. Retrieved from https:/ / www.researchgate.net/publication/324900048

Zuhairi, A., \& Hidayanti, I. (2016). The strategies of Indonesian junior high school students in learning listening skill. Arab World English Journal, 7(4), 117 - 124. Retrieved from www.awej.org/index.php/volume-7-2016/70.../1046-alfan-zuhairi-ika-hidayanti.

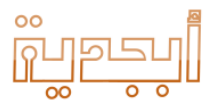

